\title{
Salud renal para todos en todos lados - de la prevención a la detección y acceso equitativo a la atención
}

\author{
Kidney health for everyone everywhere - from prevention to \\ detection and equitable access to care
}

\author{
Dr. Philip Kam-Tao Li, Dr. Guillermo Garcia-Garcia, Dr. Siu-Fai Lui, \\ Dra. Sharon Andreoli, Dr. Winston Wing-Shing Fung, Dra. Anne Hradsky, \\ Dr. Latha Kumaraswami, Dr. Vassilios Liakopoulos, Dr. Ziyoda Rakhimova, \\ Dr. Gamal Saadi, Dra. Luisa Strani, Dr. Ifeoma Ulasi y Dr. Kamyar Kalantar-Zadeh \\ en representación del World Kidney Day Steering Committee
}

\section{RESUMEN}

La enfermedad renal crónica (ERC) será la 5. ${ }^{\text {ta }}$ causa más común de años de vida perdidos para 2040. Su comienzo y progresión son, con frecuencia, prevenibles. La campaña del Día Mundial del Riñón 2020 resalta la importancia de las intervenciones preventivas. La prevención primaria debe focalizarse en modificar los riesgos y reducir la exposición a factores ambientales y nefrotoxinas. El control de la tensión arterial y de la glucemia deberían ser una de las principales intervenciones en personas con enfermedad renal pre-existente. El manejo de las comorbilidades (uremia, enfermedad cardiovascular) es altamente recomendado para evitar o postergar el uso de diálisis o trasplante renal. Con frecuencia faltan políticas específicas dirigidas a la educación, la pesquisa, el manejo y el tratamiento de la ERC.

Es urgente aumentar la concientización sobre la importancia de medidas preventivas en la población, los profesionales y los responsables de políticas de salud a nivel mundial.

Palabras clave: enfermedad renal crónica, factores de riesgo, prevención, politicas de salud, concienciación.

En adhesión a este evento internacional, el editorial "World Kidney Day 2020" se publicó en más de 50 revistas de todo el mundo. Archivos Argentinos de Pediatría se suma a esta importante difusión internacional.

Correspondencia:

Dr. Philip Kam-Tao Li: philipli@cuhk.edu.hk y Dr. Kamyar KalantarZadeh:kkz@uci.edu

Financiamiento:

Ninguno.

Conflicto de intereses:

Ninguno que declarar.

Recibido: 16-11-2019

Aceptado: 13-12-2019
Cómo citar: Li PKT, Garcia-Garcia G, Lui SF, Andreoli S, et al. Salud renal para todos en todos lados - de la prevención a la detección y acceso equitativo a la atención. Arch Argent Pediatr 2020;118(2):e148.
Texto completo en inglés:

http://dx.doi.org/10.5546/aap.2020.eng.e148 